University of Nebraska - Lincoln

DigitalCommons@University of Nebraska - Lincoln

2005

\title{
Amphibian Research and Monitoring Initiative (ARMI): A successful start to a national program in the United States
}

\author{
Erin Muths \\ USGS Fort Collins Science Center, muthse@usgs.gov \\ Robin E. Jung \\ USGS Patuxent Wildlife Research Center \\ Larissa L. Bailey \\ USGS Patuxent Wildlife Research Center \\ Michael J. Adams \\ USGS Forest and Rangeland Ecosystem Science Center \\ P. Stephen Corn \\ USGS Northern Rocky Mountain Science Center \\ See next page for additional authors
}

Follow this and additional works at: https://digitalcommons.unl.edu/usgsstaffpub

Part of the Earth Sciences Commons

Muths, Erin; Jung, Robin E.; Bailey, Larissa L.; Adams, Michael J.; Corn, P. Stephen; Dodd, C. Kenneth Jr.; Fellers, Gary M.; Sadinski, Walter J.; Schwalbe, Cecil R.; Walls, Susan C.; Fisher, Robert N.; Gallant, Alisa L.; Battaglin, William A.; and Green, D. Earl, "Amphibian Research and Monitoring Initiative (ARMI): A successful start to a national program in the United States" (2005). USGS Staff -- Published Research. 129.

https://digitalcommons.unl.edu/usgsstaffpub/129

This Article is brought to you for free and open access by the US Geological Survey at DigitalCommons@University of Nebraska - Lincoln. It has been accepted for inclusion in USGS Staff -- Published Research by an authorized administrator of DigitalCommons@University of Nebraska - Lincoln. 


\section{Authors}

Erin Muths, Robin E. Jung, Larissa L. Bailey, Michael J. Adams, P. Stephen Corn, C. Kenneth Dodd Jr., Gary M. Fellers, Walter J. Sadinski, Cecil R. Schwalbe, Susan C. Walls, Robert N. Fisher, Alisa L. Gallant, William A. Battaglin, and D. Earl Green 


\title{
Amphibian Research and Monitoring Initiative (ARMI): A successful start to a national program in the United States
}

\author{
Erin Muths ${ }^{1,2}$, Robin E. Jung ${ }^{3}$, Larissa L. Bailey ${ }^{3}$, Michael J. Adams ${ }^{4}$, \\ P. Stephen Corn ${ }^{5}$, C. Kenneth Dodd Jr. ${ }^{6}$, Gary M. Fellers ${ }^{7}$, Walter J. Sadinski ${ }^{8}$, \\ Cecil R. Schwalbe ${ }^{9}$, Susan C. Walls ${ }^{10}$, Robert N. Fisher ${ }^{11}$, Alisa L. Gallant ${ }^{12}$, \\ William A. Battaglin ${ }^{13}$, D. Earl Green ${ }^{14}$ \\ ${ }^{1}$ USGS Fort Collins Science Center, Fort Collins, CO 80525, USA \\ ${ }^{2}$ Corresponding author; e-mail: erin_muths@usgs.gov \\ ${ }^{3}$ USGS Patuxent Wildlife Research Center, Laurel, MD 20708, USA \\ ${ }^{4}$ USGS Forest and Rangeland Ecosystem Science Center, Corvallis, OR 97331, USA \\ ${ }^{5}$ USGS Northern Rocky Mountain Science Center, Aldo Leopold Wilderness Research Institute, \\ Missoula, MT 59807, USA \\ ${ }^{6}$ USGS Florida Integrated Science Center, Gainesville, FL 32653, USA \\ ${ }^{7}$ USGS Western Ecological Research Center, Point Reyes National Seashore, Point Reyes, \\ CA 94956, USA \\ ${ }^{8}$ USGS Upper Midwest Environmental Sciences Center, La Crosse, WI 54603, USA \\ ${ }^{9}$ USGS Southwest Biological Science Center, Sonoran Desert Research Station, University of \\ Arizona, Tucson, AZ 85721, USA \\ ${ }^{10}$ USGS National Wetlands Research Center, Lafayette, LA 70506, USA \\ ${ }^{11}$ USGS Western Ecological Research Center, San Diego Field Station, San Diego, CA 92123, USA \\ ${ }^{12}$ EROS Data Center, Sioux Falls, SD 57198, USA \\ ${ }^{13}$ USGS Water Resources, Lakewood, CO 80225, USA \\ ${ }^{14}$ USGS National Wildlife Health Center, Madison, WI 53711, USA
}

\begin{abstract}
Most research to assess amphibian declines has focused on local-scale projects on one or a few species. The Amphibian Research and Monitoring Initiative (ARMI) is a national program in the United States mandated by congressional directive and implemented by the U.S. Department of the Interior (specifically the U.S. Geological Survey, USGS). Program goals are to monitor changes in populations of amphibians across U.S. Department of the Interior lands and to address research questions related to amphibian declines using a hierarchical framework of base-, mid- and apex-level monitoring sites. ARMI is currently monitoring 83 amphibian species (29\% of species in the U.S.) at mid- and apex-level areas. We chart the progress of this 5-year-old program and provide an example of mid-level monitoring from 1 of the 7 ARMI regions.
\end{abstract}

Key words: Amphibian decline; Amphibian Research and Monitoring Initiative, U.S. Department of the Interior; ARMI; monitoring; occupancy; proportion of area occupied. 


\section{Introduction}

Amphibians are thought to be environmental indicators, and potential links between amphibian, human and ecosystem health have been suggested (Hayes et al., 2002). Concern about worldwide amphibian declines intensified after the First World Congress of Herpetology in 1989, where scientists became aware of the scope of the problem (Blaustein and Wake, 1990; Houlahan et al., 2000; Green, 2003). The problem of amphibian decline is complex, underlying mechanisms may be elusive (Corn, 2000; Kiesecker et al., 2001), and many causes for amphibian declines have been proposed. Disease (e.g. Daszak et al., 1999; Fellers et al., 2001), ultraviolet radiation (Blaustein et al., 1998; Langhelle et al., 1999), climate change (Beebee, 1995; Donnelly and Crump, 1998; Carey et al., 2001), nonindigenous species (Fisher and Shaffer, 1996), xenobiotic chemicals such as endocrine disruptors (Sparling et al., 2000), and synergistic effects of multiple stressors (Rouse et al., 1999; Bridges and Boone, 2003) all play a role. However, loss and degradation of habitat are arguably the primary factors leading to amphibian declines (Dodd and Smith, 2003). Whereas malformations in amphibians have been reported historically, recent reports of high frequencies of malformations within populations, and the many factors that can lead to malformations, have added to the general concern about amphibians (e.g., Ouellet, 2000; Lannoo et al., 2003). Although much progress has been made, there is no definitive global answer as to why amphibians are declining.

We present the structure, methodology, and progress of a national program designed to address these issues at multiple spatial scales in the United States. We also present preliminary data from one part of the program (mid-level monitoring) to demonstrate the applicability of our methods and support our novel approach. Increased awareness and collaboration will further strengthen the program, extending the scope and building on the initial efforts of ARMI.

\section{History and objectives of ARMI}

In response to mounting evidence and concern for declines of amphibians both in the U.S. and worldwide, and to specific suggestions for national monitoring efforts using standardized methods (Gibbons et al., 1997), the U.S. Congress appropriated funding for the Amphibian Research and Monitoring Initiative (ARMI) in 2000. This multi-faceted initiative is implemented by two agencies in the U.S. Department of the Interior: U.S. Geological Survey and U.S. Fish and Wildlife Service. We focus here on USGS, where expertise from biology, water, and geography disciplines are utilized to address ARMI objectives (http://armi.usgs.gov/). The objectives of ARMI are five-fold (fig. 1): 1) to establish a network of U.S. Department of the Interior lands on which to monitor the status of and changes in the distribution and abundance of amphibian species and communities in the U.S.; 2) to gather information about environmental conditions likely to affect amphibians; 3) to understand the scope and severity of amphibian declines throughout the U.S.; 4) to 


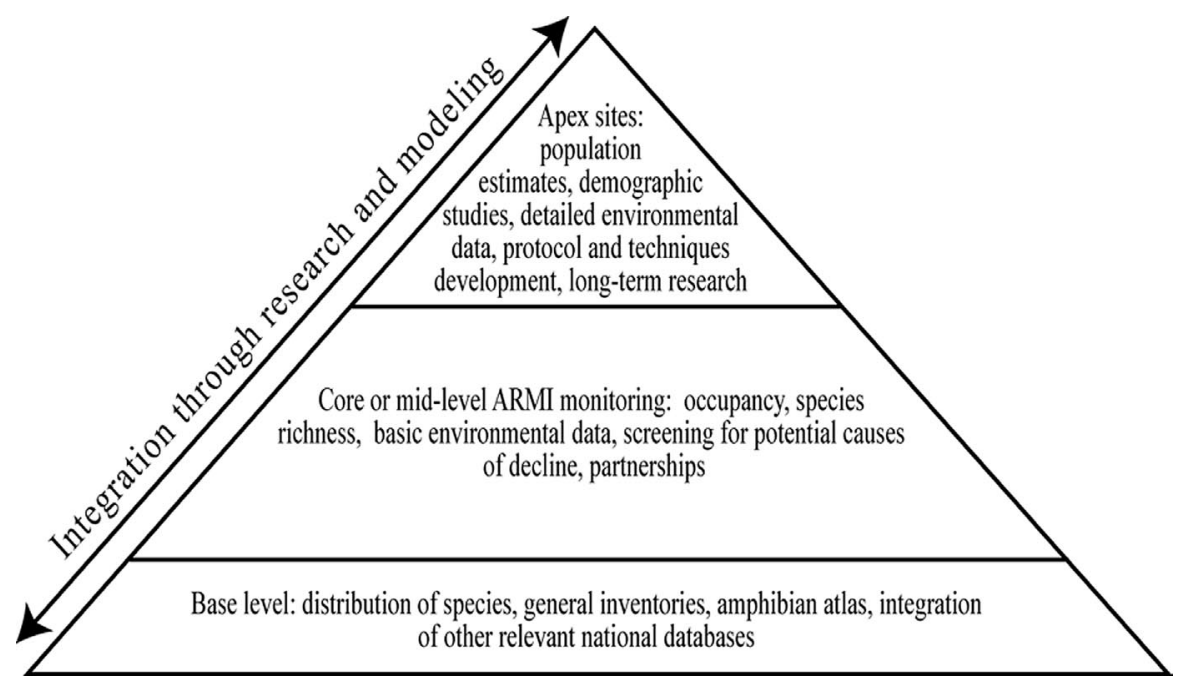

Figure 1. The conceptual model for ARMI. Research and monitoring are integrated across.

conduct research that identifies causes of amphibian declines, population changes, malformations, and diseases, should they be found; and 5) to provide essential scientific information to support management actions to arrest or reverse declines, malformations, and disease in amphibian populations. ARMI scientists use broadscale surveys with well-defined areas of inference and long-term monitoring to address the first three goals, and specific hypothesis-driven research to address the fourth and fifth goals.

\section{ARMI structure}

Only two native amphibians occur across the breadth of North America, the wood frog (Rana sylvatica), and the tiger salamander (Ambystoma tigrinum). The bullfrog (R. catesbeiana) also now has a range that spans the continent, but this species is nonindigenous west of the Great Plains (Bury and Whelan, 1984). The regionalization of amphibian distributions poses a challenge to developing a national monitoring plan. Specialized sampling techniques are often required to detect and monitor different species of amphibians, and no single technique is adequate for all species, habitats, or objectives (e.g. Heyer et al., 1994). The diversity of amphibians in North America, and challenges inherent in studying this group of animals favor a regional approach to monitoring and research. Hence, seven ARMI regions were established with national oversight (http://armi.usgs.gov/region.asp\#program). Biologists gather data about amphibian populations, distribution, and health; hydrologists characterize aquatic habitats and determine their vulnerability to physical and chemical stressors; and geographers use environmental modeling to map likely amphibian habitats, and apply new technology to develop interactive, web-based geographic information systems applications. ARMI also supports diagnostic work on 
amphibians at the USGS National Wildlife Health Center, examining animals from areas with malformations, disease outbreaks, and mortality events. USGS collaborators with toxicological and biometrical expertise provide crucial input on study design, analysis, and interpretation. Additional collaborators include federal partners (Bureau of Land Management, National Park Service, U.S. Fish and Wildlife Service, Department of Defense, U.S. Forest Service), non-governmental organizations, state and local agencies, and academia. Information about specific projects and results is available at the ARMI website (http://armi.usgs.gov/).

To use the regional and national data effectively, scientists have developed a comprehensive relational database. Electronic handheld devices are being used in most regions to reduce error and data entry effort. Multiple pathways are being developed to enter data into and access the database, including the internet, and direct data uploads from handheld devices to a server, all with the level of security demanded of U.S. Department of the Interior and other government agencies.

The organization of ARMI may be envisioned as a pyramid with three levels - base, mid, and apex (fig. 1; Corn et al., 2005). Integration of information among these three levels will occur as data accumulate. The mid-level of the ARMI pyramid provides the core framework for the program and addresses ARMI objectives 1, 2, 3 and 5. Monitoring amphibians at the mid-level is coordinated at a moderate number of areas throughout the country (e.g., individual National Parks or National Wildlife Refuges), identified a priori, where amphibian habitats are sampled and inferences drawn about the occurrences of select species within the area. The main variable is the probability of occupancy (MacKenzie et al., 2002, 2003). Estimating occupancy and its variance requires multiple visits to sites (e.g., ponds, streams) during the sampling season to estimate 'detectability', or the probability of detecting a species at occupied sites (see below). Species richness is another variable of interest in areas with high diversity, such as the southeastern U.S. Specific mid-level objectives are to provide: 1) spatial and temporal estimates of change in species occupancy within the area of inference (e.g. park); and 2) information for modeling amphibian and environmental stressor associations within the areas of inference, and to map such associations at regional levels.

Collaborative efforts with other federal, state and private partners can extend the work to build a more comprehensive national monitoring program. Design and implementation of this framework is modular, an approach that takes advantage of historical and current research programs where study sites were chosen subjectively. The program also provides the option of extending these specific efforts to additional land units. Although the non-random choice of a monitoring area will limit the level of inference to that particular land unit, substantial information is provided to resource managers of the selected areas. Results can also be pooled and summarized to provide information on regional and national trends, with the caveat that they do not represent lands that have not been sampled.

The apex of the ARMI pyramid represents intensive long-term monitoring or research at a small number of sites, and addresses objectives 2, 4, and 5. Project 
goals at apex-level sites vary considerably within and between regions, but fall generally into two categories: 1) collection of demographic and life history data for selected amphibians; and 2) studies of relationships between environmental changes and changes in demographic and life history characteristics of amphibians over time. The development of monitoring protocols and techniques is a secondary goal, for example, we lack basic knowledge of how best to monitor some species (e.g., riverine salamanders) and detect amphibian disease in the environment.

The base of the pyramid is built on inventories that are geographically extensive (e.g., national) in scope, and thus collect coarse data. While information gathered at the base level will be critical in developing a truly nationwide picture of amphibian decline, the ARMI mandate is to monitor amphibians on U.S. Department of the Interior lands, a stratification that is significantly biased, with $>75 \%$ of the 507 million acres of the Department of the Interior lands located in the west (http://www.doiu.nbc.gov/orientation/facts.cfm). Another challenge is the disparity in species richness across the United States; for example, the southeast, with relatively little federal land, has far greater species richness than the Rocky Mountains. Additionally, funding levels restrict the application of a complete sampling of all U.S. Department of the Interior lands. These factors constrain efforts at the base level of the pyramid to a peripheral component of the ARMI program; however, potential sources of information for the base of the pyramid include Frogwatch USA (http://www.nwf.org/frogwatchUSA/), the North American Amphibian Monitoring Program (http://www.pwrc.usgs.gov/naamp/), and the ARMI National Amphibian Atlas (http://www.mp2-pwrc.usgs.gov/armiatlas/). While these programs have limited applicability in statistical analyses, they play an important role in engaging the public in issues of amphibian decline.

Research (objectives 4 and 5) complements the base-, mid-, and apex- level programs. ARMI has contributed to the development of new methods for designing monitoring and analyzing results (Bailey et al., 2004; MacKenzie and Bailey, 2004; MacKenzie et al., 2002, 2003, 2004). ARMI also supports long-term studies to identify causes of amphibian malformations, population perturbations, or declines, and is funding a landscape-scale assessment of stressors in relation to amphibian presence. Short-term projects, funded competitively, address specific research questions such as the prevalence of disease in amphibians along the Continental Divide, techniques development, and amphibian presence at historic sites (e.g., Wente et al., in press). ARMI research has resulted in recent publications on a variety of species (e.g., Fellers et al., 2001; Sparling et al., 2001; Corn and Muths, 2002; Palen et al., 2002; Adams et al., 2003; Bridges and Boone, 2003; Dodd, 2003; Muths et al., 2003).

Below, we present an overview of the data collected by ARMI researchers and an example of a mid-level monitoring analysis from the Rocky Mountain Region of ARMI. The purpose of the mid-level example is to: 1) briefly review and demonstrate methods for unbiased estimation of occupancy, and 2) describe the field design for mid-level monitoring in one ARMI region. We emphasize that 
this is a simple example using only limited habitat and environmental information. As we continue to integrate our program with collaborators, information about water quality, pollutant and contaminant levels, disease, and the presence of invasive species will be incorporated into the analyses to help us understand factors contributing to amphibian declines.

\section{ARMI progress}

To illustrate the range of coverage by ARMI scientists, we assembled data from 2002 as a representative year for the program. During 2002, mid-level monitoring was conducted in 17 states, and apex-level monitoring occurred in 20 states. Overall, ARMI investigations occurred in 28 states. Of the 284 (103 frogs and toads, 181 salamanders) amphibian species recognized in the U.S. (excluding territories), researchers surveyed for 55 species (19\%) at mid-level sites, 67 species (24\%) at apexlevel sites, and 83 species (29\%) combined (table 1). Researchers studied 56/103 (54\%) of the frogs and 27/181 (15\%) of the salamander species in the U.S. The amphibian families best-represented include those that breed mainly in lentic (nonflowing) waters, such as bufonids (toads), hylids (tree frogs), ranids (true frogs) and ambystomatid (mole) salamanders. Less effort has focused on terrestrial and lotic species (plethodontid salamanders) or those that occur in habitats that are especially difficult to sample (sirens) (table 1). Survey effort is somewhat biased, due primarily to the distribution of U.S. Department of the Interior lands in relation to amphibian ranges and the legacy of historical effort on species of regional interest.

\section{Example of mid-level monitoring and analysis}

Although methods for surveying and monitoring amphibian species are documented (e.g., Heyer et al., 1994, Olson et al., 1997), these methods tend to rely on various forms of count data. Count data can be highly variable, leading to low power for assessments of change; count data are frequently biased by unmeasured differences in detection probabilities across time or space. Detection is particularly troublesome in monitoring amphibians, especially for rare salamanders and cryptic species such as frogs that vocalize under specific environmental conditions (e.g., only after heavy summer rains). An unbiased estimate of population change requires that the numbers of animals recorded reflect a constant proportion of the true population size across study sites and years. If this is not the case, i.e., if capture probabilities vary across space and time, comparative tests based solely on counts of individuals are invalid (Conn et al., 2004).

ARMI's mid-level monitoring uses an assessment of site occupancy based on detection/non-detection data that produces an unbiased estimate of the proportion of sites occupied, detectability, and standard errors associated with these estimates (MacKenzie et al., 2002). Detection/non-detection data are collected more reliably 
ARMI: A successful start to a national program

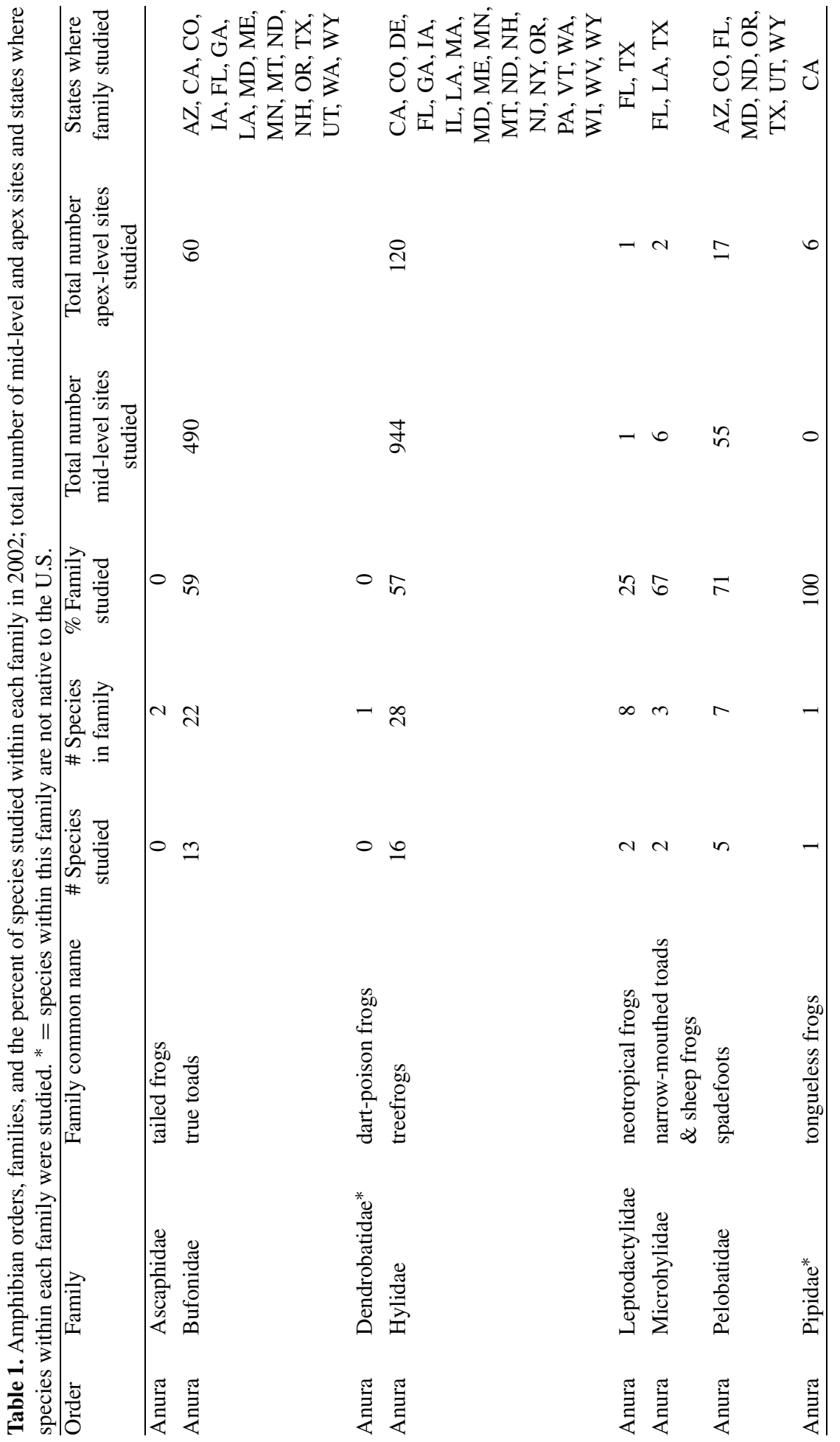




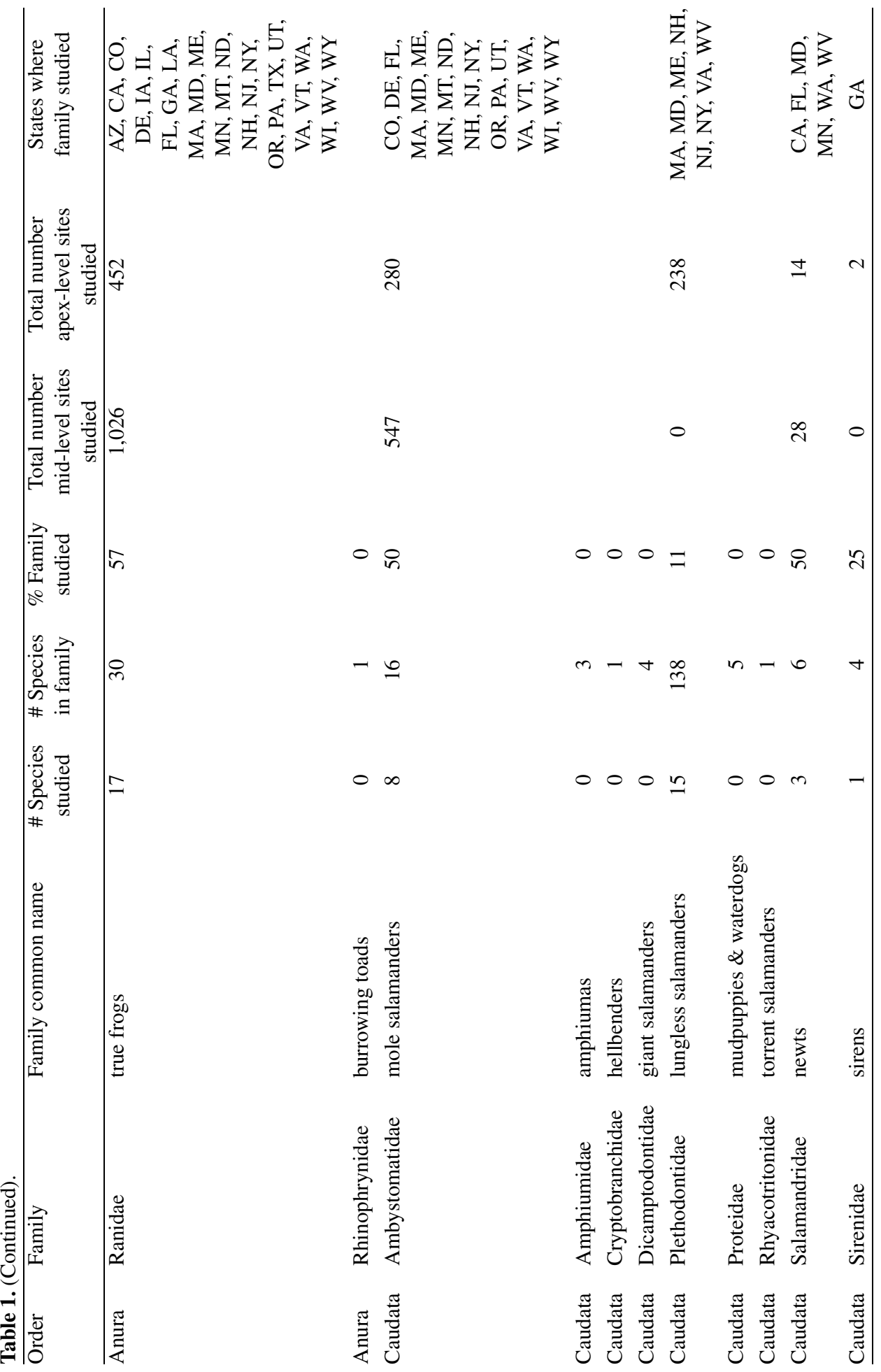


and easily than counts or estimates of population size and do not require laborintensive methods such as marking or removing animals. Collecting data for occupancy analysis does not typically require sophisticated field techniques for many species, and protocols are implemented more easily by collaborators. MacKenzie et al. (2002) incorporated detection probability directly into the estimation procedure, yielding unbiased estimates of the proportion of sites occupied, even when a species is missed or overlooked during some surveys or at some sites. This is a relatively new approach that has only been applied recently to amphibians (MacKenzie et al., 2002, 2003, 2004; Bailey et al., 2004). This approach lends itself readily to the incorporation of time and site-specific covariates (e.g., habitat, environmental, or disease conditions) that may affect the probability that an amphibian occupies a given site or is detected at occupied sites.

All mid-level monitoring data meet the following criteria: 1) the area of inference is determined prior to the surveys; 2) the survey locations are selected using a probabilistic design; 3) detectability is estimated by conducting at least 2 surveys at as many sites as possible during the period when species are available for detection; and 4) based on existing knowledge about amphibian life history and population dynamics, a priori hypotheses are used to test the influence of covariates on occupancy and detectability. Program PRESENCE (http://www.proteus.co.nz/) can be used to explore hypotheses and estimate relevant parameters. Informationtheoretic methods (Akaike Information Criteria, AIC) are then used to assess multiple competing models (Akaike, 1973; Burnham and Anderson, 2002).

We present a preliminary example of mid-level data analyses using a subset of site and sampling covariates that might influence occupancy and detection probability. To be consistent with literature written on these methods, we introduce readers to some basic notation; first, we define 2 parameters: $\psi$ denotes the probability a species is present at (i.e. occupies) a site and $p$ is the probability a species is detected at an occupied site. Site-specific covariates do not change across sampling occasions within years (e.g., many habitat variables) and may influence either occupancy or detection probabilities. Sampling covariates (e.g., water temperature, weather) often change for each sampling occasion and may influence detection probability only. We compiled detection (1) and nondetection (0) data at each visit to each site for our target species (table 2). A goodness-of-fit test is available in PRESENCE to assess how well the global or most parameterized model represents the data, and whether the data are overdispersed, in which case a variance inflation factor can be estimated and used to adjust standard errors and model selection procedures (Burnham and Anderson, 2002; MacKenzie and Bailey, 2004). More detailed descriptions of occupancy estimation methods are available elsewhere (MacKenzie et al., 2002, 2003, 2004; MacKenzie and Bailey, 2004).

In the Rocky Mountain region, Glacier National Park (N.P.) and Rocky Mountain N.P. are 2 of our mid-level monitoring areas. The range of inference for each is within park boundaries. We sampled using a set of hierarchically nested catchments from the USGS Elevation Derivatives for National Applications Project (Kost and 
Table 2. Estimates of occupancy $(\psi)$ and detection probabilities $(p)$ based on the 'best' model from AIC selection methods for each species and location. Constant parameters are reported as estimates and standard errors (adjusted for overdispersion, if necessary). Parameters that are functions of covariates $\left(^{*}\right)$ are reported as the average of the estimates of the parameter for each individual site or sampling occasion; Naïve estimate is the number of sites where the species was detected divided by the total number of sites sampled. Models could not be fitted to Rocky Mountain National Park data for boreal toads and wood frogs in 2002 or to Glacier National Park data for boreal toads in 2003 due to low numbers of detections.

\begin{tabular}{lccc}
\hline & $\begin{array}{c}\text { Occupancy } \\
\psi(\mathrm{SE})\end{array}$ & $\begin{array}{c}\text { Detectability } \\
p(\mathrm{SE})\end{array}$ & Naïve estimate \\
\hline GLACIER NATIONAL PARK & & & \\
Long-toed salamander (2002) & $0.560(0.065)^{\mathrm{a}}$ & $0.652(0.068)$ & 0.379 \\
Long-toed salamander (2003) & $0.592(0.055)^{\mathrm{a}}$ & $0.739(0.059)$ & 0.483 \\
Columbia spotted frog (2002) & $0.379(0.101)^{\mathrm{a}}$ & $0.510(0.018)^{\mathrm{b}}$ & 0.139 \\
Columbia spotted frog (2003) & $0.259(0.049)^{\mathrm{a}}$ & $0.938(0.007)^{\mathrm{a}}$ & 0.233 \\
Boreal toad (2002) & $0.102(0.035)^{\mathrm{a}}$ & $0.696(0.019)^{\mathrm{b}}$ & 0.062 \\
Boreal toad (2003) & NA & NA & 0.120 \\
ROCKY MOUNTAIN NATIONAL PARK & \multicolumn{3}{|c}{} \\
Wood frog (2003) & $0.066(0.037)$ & $0.866(0.127)$ & 0.065 \\
Chorus frog (2002) & $0.023(0.013)$ & $0.712(0.184)$ & 0.021 \\
Chorus frog (2003) & $0.187(0.128)$ & $0.284(0.206)$ & 0.089 \\
Boreal toad (2002) & NA & NA & 0.007 \\
Boreal toad (2003) & NA & NA & 0.000 \\
\hline
\end{tabular}

\footnotetext{
${ }^{\text {a }}$ Parameter probabilities are a function of vegetative cover.

${ }^{\mathrm{b}}$ Detection probabilities are functions of vegetative cover and Julian date of survey.

${ }^{\mathrm{c}}$ Wood frogs occur only on the western side of the continental divide in Rocky Mountain National Park; therefore, our area of inference for this species is only the west side of the park.
}

Kelly, 2001). Catchments were overlaid onto National Wetlands Inventory maps (http://wetlands.fws.gov) and aggregated to include 10-50 identifiable water bodies, resulting in 79 "drainages" (= mid-level sample units) in Glacier N.P. and 40 in Rocky Mountain N.P. Each year, we randomly select a new set of drainages using a scheme that ensures spatial balance. However, sampling the same units every year is a preferred method for determining long-term occupancy trends and the Rocky Mountain Region has moved towards this approach.

Every accessible water body in the selected drainages was surveyed at least once, with a subset of Glacier N.P. or all of the Rocky Mountain N.P. sites surveyed $\geqslant 2$ times to estimate detection probabilities. Visual encounter surveys (Heyer et al., 1994) were used to search for all life stages of amphibians (eggs, larvae, adults) in accessible portions of the water body, using dip nets to sample areas with limited visibility. Site-specific (e.g., vegetative cover) and sampling (e.g., water temperature) covariates were recorded for all surveys. In Glacier N.P., we surveyed 325 (2002) and 116 (2003) water bodies or sites in 17 drainages; in Rocky Mountain N.P., we surveyed 140 (2002) and 79 (2003) sites in 15 drainages. Surveys yielded long-toed salamanders (Ambystoma. macrodactylum), boreal toads 
(Bufo boreas), and Columbia spotted frogs (Rana luteiventris) in Glacier N.P., and boreal toads, wood frogs, boreal chorus frogs (Pseudacris maculata), and tiger salamanders (Ambystoma tigrinum) in Rocky Mountain N.P. There was a high number of $0 \mathrm{~s} \mathrm{(no} \mathrm{amphibian} \mathrm{detections)} \mathrm{in} \mathrm{the} \mathrm{data,} \mathrm{which} \mathrm{is} \mathrm{not} \mathrm{surprising} \mathrm{given}$ the generally depauperate amphibian fauna in the Rocky Mountains.

We fit a set of five models to detection/nondetection data for each of the three target species in Glacier N.P. Occupancy probability was modeled as constant across all sites (denoted $\psi($.$) ) or as varying according to vegetative cover, \psi(\mathrm{Veg})$. Detection probability was modeled as constant across all sites and sample occasions (denoted $p($.$) ), or as varying with time of year according to Julian date p$ (Date), across sites according to vegetative cover $p$ (Veg), or across both time and sites according to these same covariates, $p$ (Veg, Date) (table 3A). We selected these 2 covariates because eggs and larvae are more difficult to detect with increased cover (Veg) and most pond breeding amphibians are more evident at certain times during the breeding season (Date). However, these are only examples of any number of environmental variables that may affect amphibian detection or site occupancy. Further analyses may include potential stressors and other covariates. For each data set (species and year combination) we performed a goodness-of-fit test with the most parameterized model using PRESENCE. Overdispersion was detected in two datasets; thus, we used $\mathrm{QAIC}_{\mathrm{c}}$ for model selection for these species and adjusted standard errors accordingly (table 3; Burnham and Anderson, 2002; MacKenzie and Bailey, 2004). Evidence for overdispersion in the data suggests that additional or alternative covariates should be considered to improve the model.

The 2002 and 2003 long-toed salamander data were best fit by a model that described the probability of occurrence as an increasing function of vegetative cover in the pond, while detection probability appeared relatively constant across sites and sampling occasions (table 3A). Vegetative cover also appeared to be an important covariate in estimates of occupancy and detection probability for boreal toads and Columbia spotted frogs (table 3A). Occupancy probabilities for boreal toads (2002) declined as vegetative cover increased, while detection probabilities increased with Julian date. The boreal toad data for 2003 were too sparse to fit models adequately. The relationship between vegetative cover and occupancy of Columbia spotted frogs is unclear. While model selection methods suggested that vegetative cover was important in estimates of occupancy (table 3A) the data suggest a negative relationship for sites sampled in 2002 and a positive relationship for sites sampled in 2003. Each data set represents a snapshot in time of a continuous process and it is possible that either the positive (2003) or negative (2002) effect is spurious. As more long-term data are collected the strength and direction of the relationship between vegetative cover and probability of occupancy for Columbia spotted frogs will emerge.

Due to the paucity of data for all target species in Rocky Mountain N.P., we were unable to test the possible influence of covariates on either detection or occupancy probabilities. We fit two models to chorus frog data in 2003; both models assumed that occupancy probability was constant across all sites, but detection probability 
Table 3. Set of competing models with selection and fit statistics for: (A) Glacier National Park including the long-toed salamander (Ambystoma macrodactylum), Columbia spotted frog (Rana luteiventris) and boreal toad (Bufo boreas) and (B) Rocky Mountain National Park for the chorus frog (Pseudacris maculata). Occupancy probability was modeled as constant across all sites (denoted $\psi($.$) )$ or varied according to vegetative cover, $\psi(\mathrm{Veg})$. Detection probability was modeled as constant across all sites and sample occasions (denoted $p()$.$) or varied according to Julian date p$ (Date), vegetative cover $p(\mathrm{Veg})$, or both $p$ (Veg, Date). $\mathrm{K}$ is the number of parameters in each model; $\hat{c}$ is the variance inflation factor estimated using a goodness-of-fit (GOF) test performed on the most parameterized model in the candidate model set (MacKenzie and Bailey, 2004). Model selection was based on $\mathrm{AIC}_{\mathrm{c}}$, or $\mathrm{QAIC}_{\mathrm{c}}$ if overdispersion was detected (i.e. if $\hat{c} \gg 1.0$ ). The model with the lowest $\Delta \mathrm{IC}_{\mathrm{c}}$ is considered 'best' and weight is the relative support for each model. These weights sum to 1.0 for each data set (species-year combination).

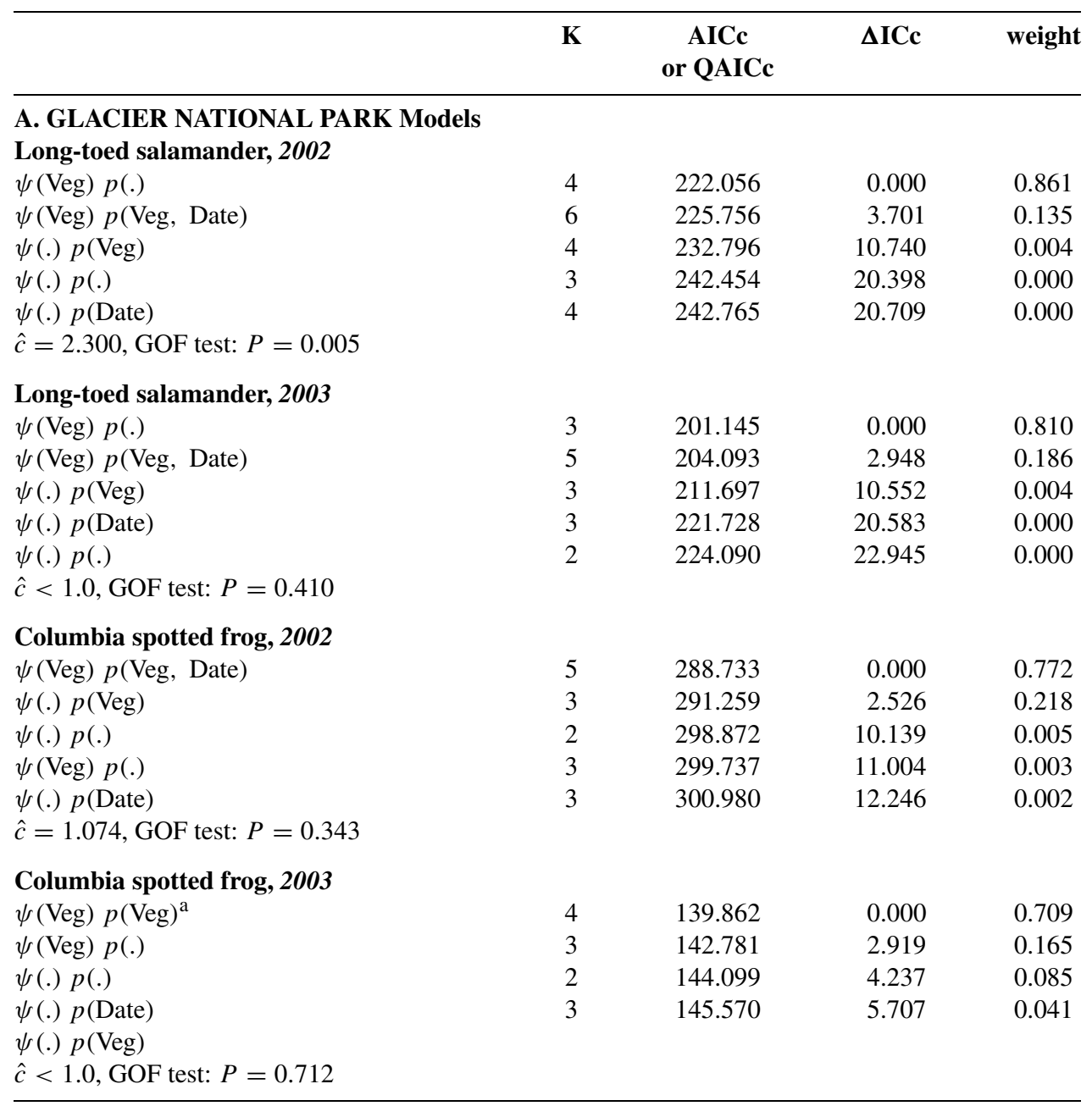

${ }^{\mathrm{a}} \psi$ (Veg Cover) $p$ (Veg Cover, Julian Date) model would not converge for this data set, thus $\psi$ (Veg Cover) $p$ (Veg Cover) was used for goodness-of-fit test. 
Table 3. (Continued).

\begin{tabular}{|c|c|c|c|c|}
\hline & $\mathbf{K}$ & $\begin{array}{l}\text { AICc } \\
\text { or QAICc }\end{array}$ & $\Delta \mathrm{ICc}$ & weight \\
\hline \multicolumn{5}{|l|}{ Boreal toad, 2002} \\
\hline$\psi($ Veg $) p($ Veg, Date $)$ & 6 & 109.593 & 0.000 & 0.301 \\
\hline$\psi($ Veg $) p()$. & 4 & 110.304 & 0.711 & 0.211 \\
\hline$\psi() p.($ Date $)$ & 4 & 110.617 & 1.024 & 0.180 \\
\hline$\psi() p.()$. & 3 & 110.724 & 1.132 & 0.171 \\
\hline $\begin{array}{l}\psi(.) p(\text { Veg Cover }) \\
\hat{c}=1.555 \text {, GOF test: } P=0.166\end{array}$ & 4 & 111.148 & 1.555 & 0.138 \\
\hline \multicolumn{5}{|c|}{$\begin{array}{l}\text { B. ROCKY MOUNTAIN NATIONAL PARK Models } \\
\text { Chorus frog, } 2003\end{array}$} \\
\hline$\psi() p.()$. & 2 & 69.075 & 0.000 & 0.933 \\
\hline $\begin{array}{l}\psi(.) p(\text { Date }) \\
\hat{c}<1.0, \text { GOF test: } P=0.482\end{array}$ & 4 & 74.344 & 5.269 & 0.067 \\
\hline
\end{tabular}

was either constant or varied among sampling occasions (table 3B). Our results suggest that there is little seasonal variation in detection probabilities for this species, as the constant detection model garnered the majority of support $\left(\mathrm{AIC}_{\mathrm{c}}\right.$ weight $=0.93$, table 3B). We were able to fit only the simplest model, which assumes constant occupancy and detection probabilities, to data for the remaining species from Rocky Mountain N.P. (table 2). Boreal toads were only detected at one site in 2002 and at no sites in 2003 (table 2). An occupancy approach may not be the most appropriate method to assess species that are scarce or extremely localized. Boreal toads are rare in the park, endangered in the State of Colorado (Jungwirth, 2003), and declining in the area of inference (Muths et al., 2003), and wood frogs are extremely localized in their occurrence. In these cases, a different survey strategy should be chosen, such as abundance estimation (apex-level monitoring) at sites where the species is known to occur. Data for salamanders were incomplete and are not presented.

Results from both parks indicate that detection probabilities differ among species, years, and, in some cases, covariates. Occupancy estimates were slightly higher than naïve estimates for all species assessed (table 2). In general, we found larger discrepancies between model and naïve estimates of occupancy for species with low detection probabilities. These results are examples of how occupancy and associated analysis methods can be applied. Most ARMI regions have mid-level monitoring areas and are using occupancy as their primary state variable. There will soon be sufficient data to estimate trends in occupancy and to evaluate the influence of environmental covariates on those trends using techniques similar to the analysis described above (MacKenzie et al., 2003). While the designation of areas of inference, site selection, and methodology varies among mid-level monitoring areas, the trend estimates will be comparable and will allow regional and national summaries of the status of amphibians. 


\section{Discussion}

Quantitative information on the occurrence of amphibians, long-term data on changes in the numbers of populations across the landscape, and answers to specific questions related to amphibian decline have been addressed within the framework of and in response to ARMI objectives. With a uniform state variable (occupancy) and long-term coordinated monitoring efforts, we will contribute critical knowledge about amphibians at local, regional and national scales. Acquiring information that is nation-wide in scope can be accomplished using this modular approach (Corn et al., 2005), where ARMI provides a framework and collaborators increase the area surveyed and thus, the area of inference. For example, Glacier N.P. and Rocky Mountain N.P. are adjacent to national and state forests. The White River National Forest in Colorado is using methods designed by ARMI to monitor amphibians (M. Lacy, U.S. Forest Service, pers. comm.), and the national forests in Montana are being inventoried for amphibians using a probabilistic sampling design and survey methods similar to those used by ARMI. Data collected will be incorporated into the ARMI database (B.A. Maxell, Montana Natural Heritage Program, Helena, pers. comm.). Collaborations allow a more comprehensive national monitoring program and facilitate the exchange of information necessary to make informed management decisions.

While U.S. Department of the Interior agencies and other managers consider long-term monitoring essential, they also have short-term information needs, and funding opportunities are more likely to be tied to short-term rather than long-term objectives. ARMI provides information that can be used for long-term as well as short-term adaptive management of amphibians and the resources critical to their survival. The ARMI program is designed to be modular so that discrete portions can stand alone or build on one another, facilitating management from the survey unit to the regional level. Examples of ARMI research and monitoring projects that provide information for short-term adaptive management include the use of culverts as movement corridors, translocation, and the efficacy of grazing enclosures on Columbia spotted frog populations in the Pacific Northwest; the short-term effects of fire on tree frogs at the Lower Suwannee National Wildlife Refuge; and the translocation of Chiricahua leopard frogs (R. chiricahuensis) in the face of imminent extirpation at sites in Arizona. Each of these projects has benefited from collaborations between ARMI and state and federal agencies. As monitoring data accumulate, a long-term picture will emerge and contribute to management decisions and planning exercises such as the National Park Service's Inventory and Monitoring and Vital Signs programs (http://www.cnr.uidaho.edu/rrt496/Vital_signs_brochure.pdf).

\section{Conclusion}

Data collection within the multi-scale ARMI paradigm is addressing the need for quantitative and statistically rigorous, broad-scale, baseline information on 
amphibian populations. This has the advantage of a flexible structure so managers, collaborators and agencies can cooperate to enlarge areas of inference and to use quantitative methods that assure our ability to evaluate status and trends effectively. The paradigm allows for research and site-specific investigations that complement monitoring efforts. For more information about ARMI regions, contact information for regional scientists, and mid- and apex-level site projects, visit: http://armi.usgs.gov/.

Acknowledgements. We thank our ARMI collaborators and especially our field technicians for making this work possible. Thanks to B. Hossack and R. Scherer for discussion and assistance with analysis. We also thank D. James and R. Kearney for their leadership for ARMI, and D. MacKenzie, J. D. Nichols, C. Langtimm and others for their pioneering work towards a statistical approach to monitoring amphibians. Many thanks to D. Olson and D. Pilliod for comments that have improved the manuscript substantially.

\section{References}

Adams, M.J., Pearl, C.A., Bury, R.B. (2003): Indirect facilitation of an anuran invasion by non-native fishes. Ecol. Let. 6: 343-351.

Akaike, H. (1973): Information theory as an extension of the maximum likelihood principle. In: Second International Symposium on Information Theory, p. 267-281. Petrov, B.N., Csaki, F., Eds, Budapest, Hungary: Akademiai Kiado.

Bailey, L.L., Simons, T.R., Pollock, K.H. (2004): Estimating site occupancy and species detection probability parameters for terrestrial salamanders. Ecol. Appl. 14: 692-702.

Beebee, T.C. (1973): Observations concerning the decline of the British Amphibia. Biol. Cons. 5: 20-24.

Beebee, T.C. (1995): Amphibian breeding and climate. Nature 374: 219-220.

Blaustein, A.R., Wake, D.B. (1990): Declining amphibian populations: a global phenomenon? Trends Ecol. Evol. 5: 203-204.

Blaustein, A.R., Kiesecker, J.M., Chivers, D.P., Hokit, D.G., Marco, A., Belden, L.K., Hatch, A. (1998): Effects of ultraviolet radiation on amphibians: Field experiments. Amer. Zool. 38: 799812.

Bragg, A.N. (1960): Population fluctuations in the amphibian fauna of Cleveland County, Oklahoma, during the past twenty-five years. Southwestern Nat. 39: 323-327.

Bridges, C.M., Boone, M.D. (2003): The interactive effects of UV-B and insecticide exposure on tadpole survival, growth and development. Biol. Conserv. 113: 49-54.

Burnham, K.P., Anderson, D.R. (2002): Model selection and multi-model inference: A practical information-theoretic approach. New York, Springer-Verlag.

Bury, R.B., Dodd, Jr. C.K., Fellers, G.M. (1980): Conservation of the amphibians of the United States. Washington DC: U.S. Department of the Interior, Fish and Wildlife Service. Resource Publication 134. $34 \mathrm{p}$.

Bury. R.B., Whelan, J.A. (1984): Ecology and management of the bullfrog. Washington, D.C.: U.S. Department of the Interior, Fish and Wildlife Service. Resource Publication 155. 23 p.

Carey, C., Heyer, W.R., Wilkinson, J., Alford, R.A., Arntzen, J.W., Halliday, T., Hungerford, L., Lips, K.R., Middleton, E.M., Orchard, S.A., Rand, S.A. (2001): Amphibian declines and 
environmental change: Use of remote-sensing data to identify environmental correlates. Conserv. Biol. 15: 903-913.

Conn, P.B., Bailey, L.L., Sauer, J.R. (2004): Indexes as surrogates to abundance and presence for low abundance species. In: Sampling rare or elusive species: Concepts, designs and techniques for estimating population parameters, p. 59-74. Thompson, W.L., Ed., Washington, D.C.: Island Press.

Corn, P.S. (2000): Amphibian declines: a review of some current hypotheses. In: Ecotoxicology and amphibians and reptiles, p. 663-696. Sparling, D.W., Linder, G., Bishop, C.A., Eds, Pensacola, FL: SETAC Press.

Corn, P.S., Muths, E. (2002): Variable breeding phenology affects the exposure of amphibian embryos to ultraviolet radiation. Ecology 83: 2958-2963.

Corn, P.S., Adams, M.J., Battaglin, W.A., Gallant, A.L., James, D.L., Knutson, M., Langtimm, C.A., Sauer, J.R. (2005): Amphibian Research and Monitoring Initiative: concepts and implementation. U.S. Geological Survey. In press.

Daszak, P., Berger, L., Cunningham, A.A., Hyatt, A.D., Green, D.E., Speare, R. (1999): Emerging infectious diseases and amphibian population declines. Emerg. Infect. Dis. 5: 735-748.

Dodd, C.K., Jr. (2003): Monitoring amphibians in Great Smoky Mountains National Park. U.S. Geological Survey Circular 1258.

Dodd, C.K. Jr., Smith, L.L. (2003): Habitat destruction and alteration. Historical trends and future prospects for amphibians. In: Amphibian Conservation, p. 94-112. Semlitsch, R.D., Ed., Washington, D.C., Smithsonian Institution Press.

Donnelly, M.A., Crump, M.L. (1998): Potential effects of climate change on two neotropical amphibian assemblages. Climatic Change 39: 541-561.

Fellers, G.M., Green, D.E., Longcore, J.E. (2001): Oral chytridiomycosis in the yellow-legged frog (Rana muscosa). Copeia 2001: 945-953.

Fisher, R.N., Shaffer, H.B. (1996): The decline of amphibians in California's Great Central Valley. Conserv. Biol. 10: 1387-1397.

Gibbons, W.J., Burke, V.J., Lovich, J.E., Semlitsch, R.D., Tuberville, T.D., Bodie, J.R., Greene, J.L., Niewiarowski, P.H., Whiteman, H.H., Scott, D.E., Pechmann, J.H.K., Harrison, C.R., Bennett, S.H., Krenz, J.D., Mills, M.S., Buhlmann, K.A., Lee, J.R., Seigel, R.A., Tucker, A.D., Mills, T.M., Lamb, T., Dorcas, M.E., Congdon, J.D., Smith, M.H., Nelson, D.H., Dietsch, M.B., Hanlin, H.G., Ott, J.A., Karapatakis, D.J. (1997): Perception of species abundance, distribution, and diversity: Lessons from four decades of sampling on a government-managed reserve. Environ. Manage. 21: 259-268.

Gibbs, E.L., Nace, G.W., Emmons, M.B. (1971): The live frog is almost dead. BioScience 21: 10271034.

Green, D.M. (2003): The ecology of extinction: population fluctuation and decline in amphibians. Biol. Conserv. 111: 331-343.

Hayes, M.P., Jennings, M.R. (1986): Decline of ranid frog species in western North America: are bullfrogs (Rana catesbeiana) responsible? J. Herpetol. 20: 490-509.

Hayes, T.B., Haston, K., Tsui, M., Hoang, A., Haeffele, C., Vonk, A. (2002): Feminization of male frogs in the wild. Nature 419: 895-900.

Heyer, W.R., Donnelly, M.A., McDiarmid, R.W., Hayek, L.C., Foster, M.S. (1994): Measuring and monitoring biological diversity: standard methods for amphibians. Smithsonian Institution Press, Washington, D.C.

Houlahan, J.E., Findlay, C.S., Schmidt, B.R., Meyer, A.H., Kuzmin, S.L. (2000): Quantitative evidence for global amphibian population declines. Nature 404: 752-755.

Jungwirth, T. (Ed.). (2003): Report on the status and conservation of the boreal toad (Bufo boreas boreas) in the southern Rocky Mountains. Colorado Division of Wildlife, 6060 Broadway, Denver, CO 80216. p. 60.

Kiesecker, J.M., Blaustein, A.R., Belden, L.K. (2001): Complex causes of amphibian population declines. Nature 410: 681-684. 
Kost, J.R., Kelly, G.G. (2001): Watershed delineation using the National Elevation Dataset and semiautomated techniques. Proceedings: 2001 ESRI International User Conference, July 9-13, 2001, San Diego, CA. Environmental Systems Research Institute, Inc., Redlands, CA. See http://gis.esri.com/library/userconf/proc01/professional/papers/pap421/p421.htm.

Langhelle, A., Lindell, M.J., Nystrom, P. (1999): Effects of ultraviolet radiation on amphibian embryonic and larval development. J. Herpetol. 33: 449-456.

Lannoo, M.J., Sutherland, D.R., Jones, P., Rosenberry, D., Klaver, R.W., Hoppe, D.M., Johnson, P.T.J., Lunde, K.B., Facemire, C., Kapfer, J.M. (2003): Multiple causes for the malformed frog phenomenon. In: Multiple stressor effects in relation to declining amphibian populations. Pp. 233264. Linder, G., Krest, S., Sparling, D., Little, E., Eds, ASTM STP 1443, West Conshohocken, PA: ASTM International.

MacKenzie, D.I., Nichols, J.D., Lachman, G.B., Droege, S., Royle, J.A., Langtimm, C.A. (2002): Estimating site occupancy rates when detection probabilities are less than one. Ecology 83: 22482255.

MacKenzie, D.I., Nichols, J.D., Hines, J.E., Knutson, M.G., Franklin, A.D. (2003): Estimating site occupancy, colonization, and local extinction when a species is detected imperfectly. Ecology 84: 2200-2207.

MacKenzie, D.I., Bailey, L.L., Nichols, J.D. (2004): Investigating species co-occurrence patterns when species are detected imperfectly. J. Animal Ecology 73: 546-555.

MacKenzie, D.I., Bailey, L.L. (2004): Assessing the fit of site occupancy models. J. Agric. Biol. Envir. S. 9: 300-318.

Muths, E., Corn, P.S., Pessier, A.P., Green, D.E. (2003): Evidence for disease-related amphibian decline in Colorado. Biol. Conserv. 110: 357-365.

Olson, D.H., Leonard, W.P., Bury, R.B. (Eds.) (1997): Sampling amphibians in lentic habitats. Northwest Fauna Number 4. Olympia, WA: Society for Northwestern Vertebrate Biology.

Ouellet, M. (2000): Amphibian deformities: current state of knowledge. In: Ecotoxicology of amphibians and reptiles, p. 617-662. Sparling, D.W., Linder, G., Bishop, C.A., Eds., Pensacola, FL, SETAC Press.

Palen, W.J., Schindler, D.E., Adams, M.J., Pearl, C.A., Bury, R.B., Diamond, S.A. (2002): Optical characteristics of natural waters can protect amphibian populations from UV-B in the U.S. Pacific Northwest. Ecology 83: 2951-2957.

Rouse, J.D., Bishop, C.A., Struger, J. (1999): Nitrogen pollution: an assessment of its threat to amphibian survival. Environ. Health Persp. 107: 799-803.

Sparling, D.W., Linder, G., Bishop, C.A., Eds. (2000): Ecotoxicology of amphibians and reptiles. Pensacola, FL, SETAC Press.

Sparling, D.W., Fellers, G.M., McConnell, L.L. (2001): Pesticides and amphibian population declines in California, USA. Environ. Toxicol. Chem. 20: 1591-1595.

Wente W.H., Adams, M.J., Pearl, C.A. In press. Evidence of decline for Bufo boreas and Rana luteiventris in and around the northern Great Basin, western USA. Alytes.

Accepted: January 20, 2005. 